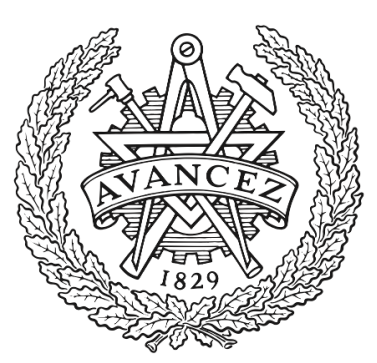

CHALMERS

UNIVERSITY OF TECHNOLOGY

\title{
Output voltage synthesis of a modular battery system based on a cascaded h-bridge multilevel inverter topology for vehicle propulsion: Multilevel
}

Downloaded from: https://research.chalmers.se, 2023-04-26 13:59 UTC

Citation for the original published paper (version of record):

Kersten, A., Baum, L., Han, W. et al (2020). Output voltage synthesis of a modular battery system based on a cascaded h-bridge multilevel inverter topology for vehicle propulsion: Multilevel pulse width modulation vs. fundamental selective harmonic elimination. 2020 IEEE Transportation Electrification Conference and Expo, ITEC 2020: 296-302. http://dx.doi.org/10.1109/ITEC48692.2020.9161658

N.B. When citing this work, cite the original published paper. 


\title{
Output Voltage Synthesis of a Modular Battery System based on a Cascaded H-Bridge Multilevel Inverter Topology for Vehicle Propulsion: Multilevel Pulse Width Modulation
}

\author{
VS. \\ Fundamental Selective Harmonic Elimination
}

\author{
Anton Kersten, Lukas Baum, Weiji Han, Torbjörn Thiringer, Massimo Bongiorno \\ Chalmers University of Technology \\ Gothenburg, Sweden \\ Email: kersten@chalmers.se
}

\begin{abstract}
Lately, the research interest for modular battery systems has increased due to the possibility of a better utilization of individual battery packs/cells and the steadily reducing costs of low voltage power electronics. This paper deals with the output voltage synthesis of a modular battery system based on a seven level Cascaded H-bridge (CHB) inverter topology used in a small passenger vehicle. Two methods are considered, Multilevel Pulse Width Modulation (MPWM) and Fundamental Selective Harmonic Elimination (FSHE). Using simulations, the inverter and battery losses, as well as the current THD, are used to assess the effectiveness of both techniques for the broad operating range of a vehicle's drivetrain. It has been shown that FSHE cannot be applied at a modulation index below 0.25 , because of the high current THD $(>>5 \%)$. Exceeding a modulation index of 0.25 , FSHE reduces the battery and inverter losses in comparison to MPWM, while maintaining an acceptable current THD. Operating at higher speeds, FSHE achieves an even better current THD than MPWM. Consequently, it seems reasonable to use a hybrid modulation technique, using MPWM at low and FSHE at higher speeds, respectively. The exact boundary between MPWM and FSHE can vary in accordance with the individual optimization weightings of current THD and drivetrain efficiency.
\end{abstract}

\section{INTRODUCTION}

Electric vehicle drive systems require highly efficient batteries and power electronics. Due to its low component count and maturity, two-level inverters are widely used [1]-[5]. Cascaded H-bridge (CHB) multilevel inverters, being popular for power system applications [6]-[8], became an interesting option [9]-[11], as first introduced by [12] for vehicle propulsion applications. Cascaded H-bridge multilevel inverters use a series connection of $\mathrm{H}$-bridge converters to achieve the desired number of output voltage levels [13]. Small battery modules can be implemented in each of the H-bridge modules to form a modular battery system, which achieves advanced possibilities for battery charge balancing, which extends the lifetime of the battery modules [14]. Additionally, the modular layout of the CHB topology has a low component count compared to other multilevel inverter topologies with the same number of voltage levels [15]. This allows for further reductions of harmonic distortions [16], electromagnetic emissions [17] and switching losses [11], [18], as well as allowing for the use of low voltage MOSFETs [19], [20]. Furthermore, multilevel inverters allow for a fault tolerant operation of the drivetrain [21] in case of single switch or battery faults. Different switching techniques are used to obtain optimal performance and minimal losses for different operating regions [22]-[24].

In [3], the authors compared a standard two-level inverter with a three-level and a five-level active neutral point clamped inverter for vehicle traction applications, showing a high potential increase in efficiency of the multilevel inverters in comparison to the two-level inverter. A similar analysis and result is shown in [11], comparing the drive cycle efficiencies of a CHB and a two-level inverter. In both [3] and [11], the output voltages were modulated using Multilevel Pulse Width Modulation (MPWM).

Therefore, this paper introduces a hybrid modulation technique for CHB multilevel inverters used for vehicle propulsion applications. At low speed (low modulation index), it seems more suitable to use multilevel pulse width modulation, whereas at high speed (high modulation index), it might be beneficial to use Fundamental Selective Harmonic Elimination (FSHE). To verify this assumption, a vehicle drivetrain using a seven level CHB and its inverter losses are modeled. Simulations are used to obtain the switching and conduction losses over the entire operating range of the vehicle's motor using multilevel pulse width modulation and fundamental selective harmonic elimination.

\section{CASCaded H-bridge Multilevel Inverter}

Passive balancing is a common technique, which is applied to propulsion battery packs, to ensure that each individual battery cell is operated within its State of Charge (SOC) 


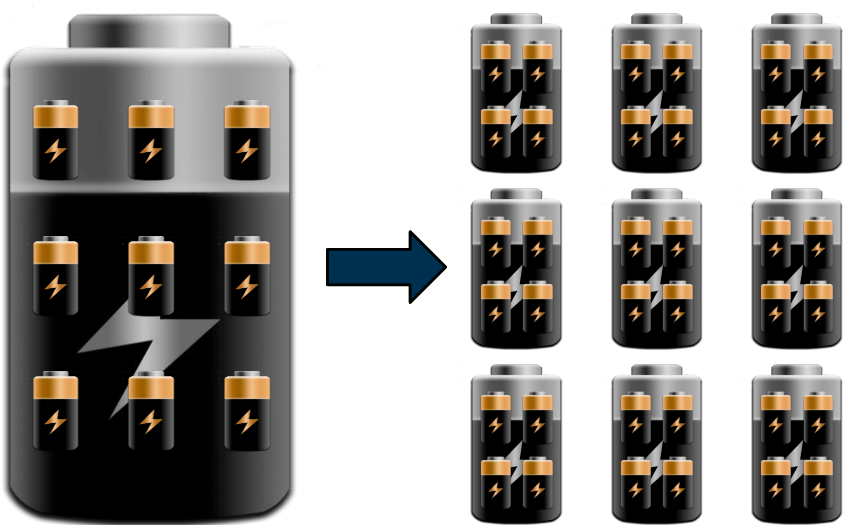

Fig. 1: Modular battery system with 9 small battery modules/packs.

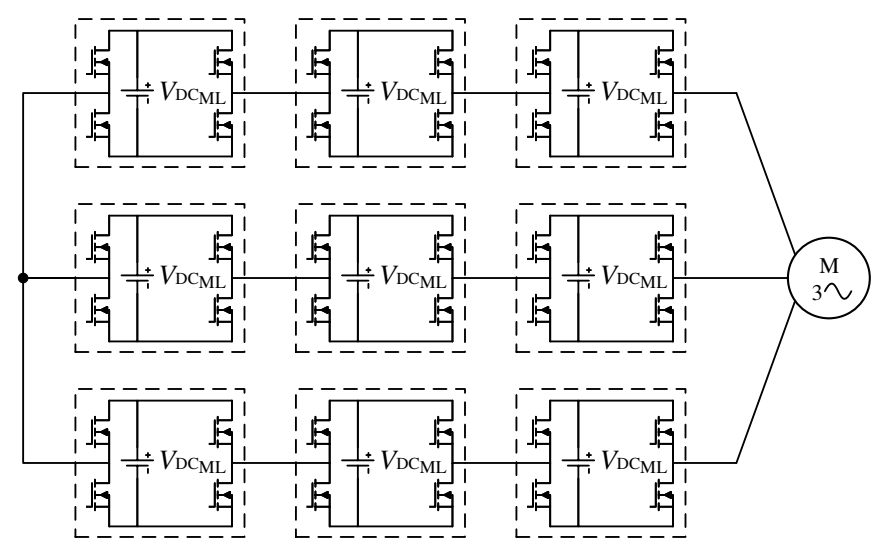

Fig. 2: Topology of a seven level CHB inverter with split battery system used for variable speed drive applications, such as vehicle propulsion.

and voltage boundaries [25]. However, since the weakest cell constrains the usable capacity of a serial battery string, it is challenging to maintain a long lifetime for high voltage batteries [26]. Hence, it might be beneficial to split the battery into small battery modules, as for example depicted in Fig. 1. According to [5], a number of 9 submodules is often selected. To combine the propulsion inverter and balancing circuitry of the individual battery modules, each battery module can be equipped with an H-bridge inverter. Connecting three $\mathrm{H}$-bridges per phase in series, a seven level CHB inverter, as shown in Fig. 2, is formed. Each $\mathrm{H}$ - bridge has four valid switching states, as can be seen in Fig. 3. As shown, the switches are always activated in pairs. If the two upper or lower switches are activated, the battery module is bypassed, as shown in Figs. 3(a) and 3(b). If the switches are operated diagonally, as shown in Figs. 3(c) and 3(d), the corresponding battery module is inserted in forward and reverse direction into the phase strand, respectively. Thus, it can be seen that each $\mathrm{H}$-bridge can create the output voltage levels according to

$$
V_{\mathrm{out}}=\left\{+V_{\mathrm{DC}},-V_{\mathrm{DC}_{\mathrm{ML}}}, 0\right\} .
$$

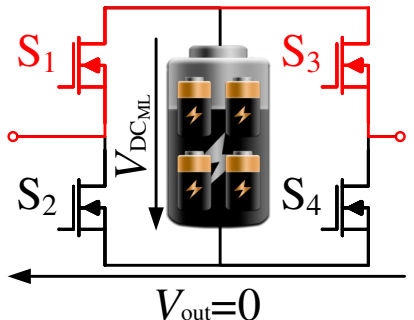

(a)

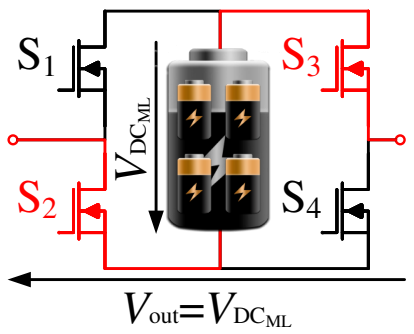

(c)

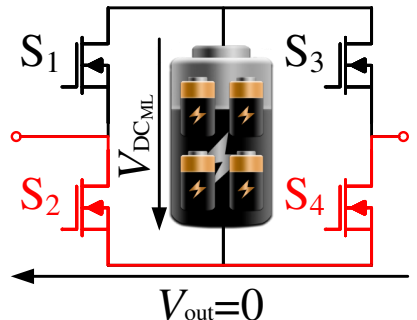

(b)

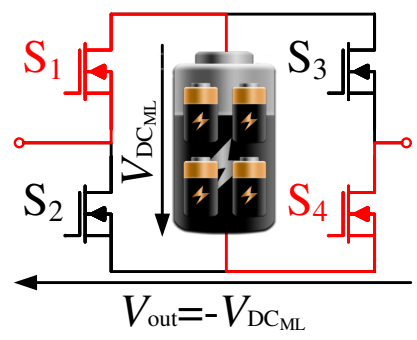

(d)
Fig. 3: Valid switching combinations of each individual $\mathrm{H}$-bridge. In (a) and (b) the battery module is bypassed. In (c) and $(\mathrm{d})$ the battery module is inserted in forward and reverse direction, respectively.

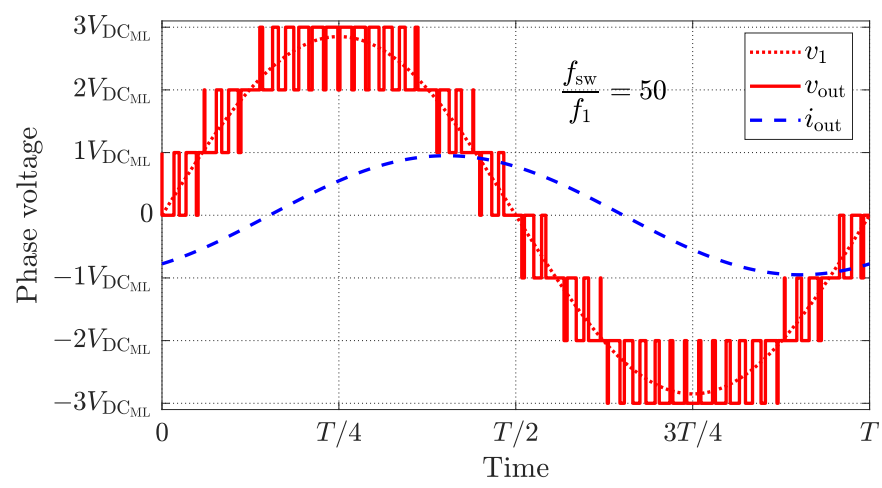

Fig. 4: MPWM: phase voltage for a seven level inverter with equal DC voltages and $M=0.95, f_{1}=200 \mathrm{~Hz}$ and $f_{\mathrm{sw}}=10 \mathrm{kHz}$.

Consequently, the output voltage of a cascaded H-bridge multilevel inverter is generated as a superposition of the output voltages of the individual H-bridge modules of each phase.

\section{A. Multilevel Pulse Width Modulation (MPWM)}

Multilevel Pulse Width Modulation, as shown in Fig. 4 is a common method to modulate the desired output voltage of a CHB inverter [27]. For each H-bridge, two triangular carrier waves are compared with the sinusoidal output voltage reference. Within the scope of this paper, Phase Disposition PWM (PD-PWM) is considered. This means, that the individual carrier waves of all $\mathrm{H}$-bridges are just level-shifted, but their phase angles are constant. A detailed description about the PD-PWM implementation can be found in [27]. In principle, 


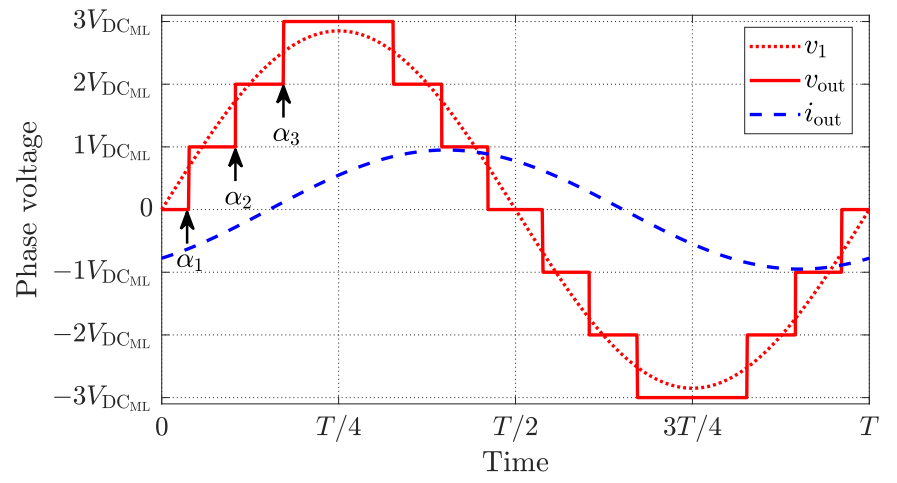

Fig. 5: FSHE: phase voltage for seven level inverter with equal DC voltages and $M=0.95$.

multilevel pulse width modulation does not significantly differ from two-level pulse width modulation. Therefore, also the injection of the optimal zero sequence voltage is considered to increase the maximum permissible output voltage by about $15 \%$ without introducing low order harmonics [27].

\section{B. Fundamental Selective Harmonic Elimination (FSHE)}

Another method to synthesize the desired output voltage of the CHB inverter is fundamental frequency switching [27], as depicted in Fig. 5. With the help of the insertion angles

$$
\alpha=\left[\begin{array}{c}
\alpha_{1} \\
: \\
\alpha_{\frac{L-1}{2}}
\end{array}\right]
$$

with $L$ being the number of output voltage levels, the output voltage of each H-bridge module per phase can be defined as

$$
V_{\text {out }, j}\left(\alpha_{j}\right)=\left\{\begin{aligned}
&+V_{\mathrm{DC}_{\mathrm{ML}} ;} \text { if } \alpha_{j} \leq \omega t \leq \pi-\alpha_{j} \\
&-V_{\mathrm{DC}_{\mathrm{ML}} ;} \quad \text { if } \pi+\alpha_{j} \leq \omega t \leq 2 \pi-\alpha_{j} \\
& 0 ; \quad \text { else }
\end{aligned}\right.
$$

with $j=1,2, \ldots \frac{L-1}{2}$. Consequently, according to [27], the phase voltage harmonics including the fundamental component can be expressed in relation to the insertion angles as

$$
V_{\mathrm{ph}, h}=\frac{8 V_{\mathrm{DC}}}{(L-1) h \pi}\left[\cos \left(h \alpha_{1}\right)+\ldots+\cos \left(h \alpha_{\frac{L-1}{2}}\right)\right]
$$

with $h=\{1,3,5, \ldots\}$ and $V_{\mathrm{DC}}=\frac{L-1}{2} V_{\mathrm{DC}_{\mathrm{ML}}}$. Optimizing the insertion angles, up to two harmonic components can be eliminated when using a seven level inverter, referred to as Fundamental Selective Harmonic Elimination [27]. This can be expressed as the following optimization problem when dealing with a three-phase inverter:

$$
\begin{array}{cl}
\underset{\alpha}{\operatorname{minimize}} & 7 \cdot\left|V_{\mathrm{ph}, 5}(\alpha)\right|+5 \cdot\left|V_{\mathrm{ph}, 7}(\alpha)\right| \\
\text { subject to } & V_{\mathrm{ph}, 1}=\frac{4 V_{\mathrm{DC}_{\mathrm{ML}}}}{\pi}\left(\cos \left(\alpha_{1}\right)+\ldots+\cos \left(\alpha_{3}\right)\right) \\
& V_{\mathrm{ph}, 1}=3 V_{\mathrm{DC}_{\mathrm{ML}}} M \\
& 0 \leq \alpha_{1} \leq \alpha_{2} \leq \alpha_{3} \leq \frac{\pi}{2}
\end{array}
$$

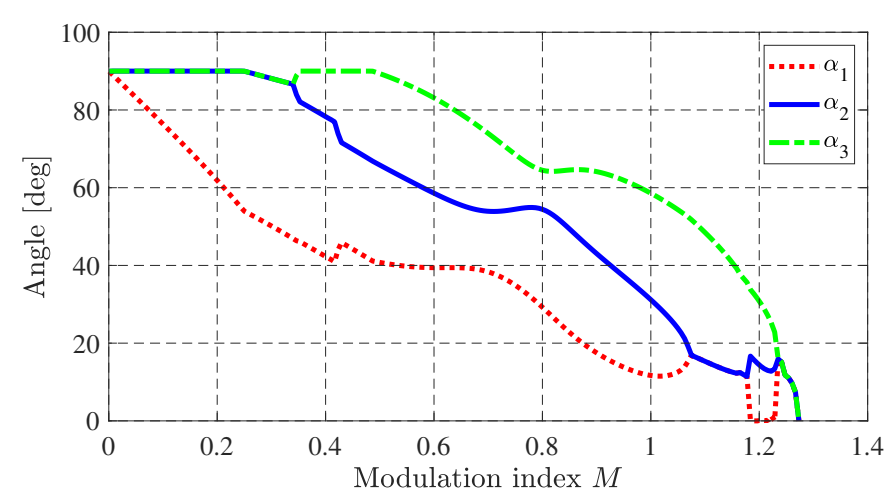

(a)

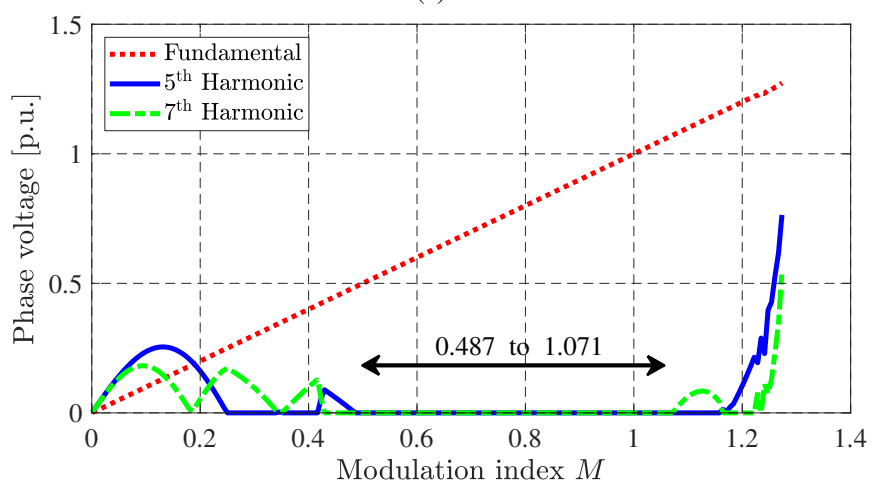

(b)

Fig. 6: (a) Optimized insertion angles and (b) resulting output components for the seven level CHB inverter.

The results of the corresponding optimization, using Matlab's fmincon-command, relative to the modulation index $M$, can be seen in Fig. 6. As can be seen, if the modulation index $M$ is between 0.487 and 1.071 , both the $5^{\text {th }}$ and the $7^{\text {th }}$ harmonic can be eliminated. If the modulation index is between 0.25 and 0.487 , just one of the selected harmonics can be eliminated. Furthermore, it can be seen, if the modulation index is below 0.25 , neither the $5^{\text {th }}$ nor the $7^{\text {th }}$ harmonic can be eliminated, since just one H-bridge module is activated to control the fundamental component.

\section{CASE SET-UP}

To analyze and assess the effectiveness of the two output voltage modulation/synthesis techniques, MPWM and FSHE, relative to the broad operating range of an electric vehicle, a reference drivetrain is modeled and simulated. A small passenger car driven by an $84 \mathrm{~kW}$ rated interior permanent magnet machine with a battery capacity of about $45 \mathrm{kWh}$ is considered. For the inverter model, data of an Infineon OptiMOS $^{\mathrm{TM}}-5$ Power-Transistor IAUT300N10S5N015 with $B V_{\mathrm{DS}}=100 \mathrm{~V}, R_{\mathrm{ds}, \text { on }}=1.5 \mathrm{~m} \Omega, I_{\mathrm{D}}=300 \mathrm{~A}$ and $T_{j, \max }=175^{\circ} \mathrm{C}$ is used. The temperature of the MOSFETs is defined as constant with $T_{\mathrm{j}}=T_{\text {coolant }}=70^{\circ} \mathrm{C}$. The battery pack is modeled based on the impedance of a reference battery cell. The chosen cylindrical 18650 high energy cell is manufactured by LG Chem. It has a nominal voltage of 


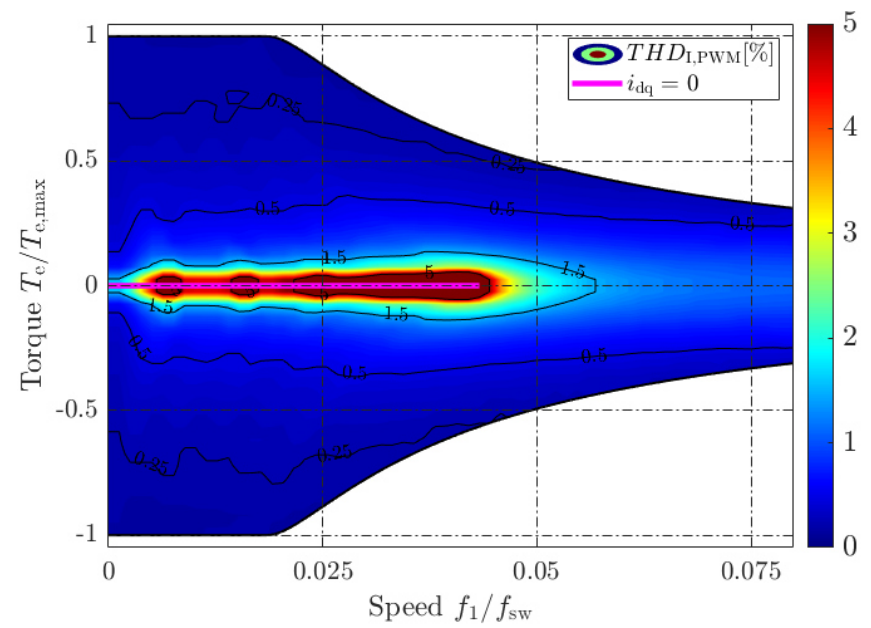

(a)

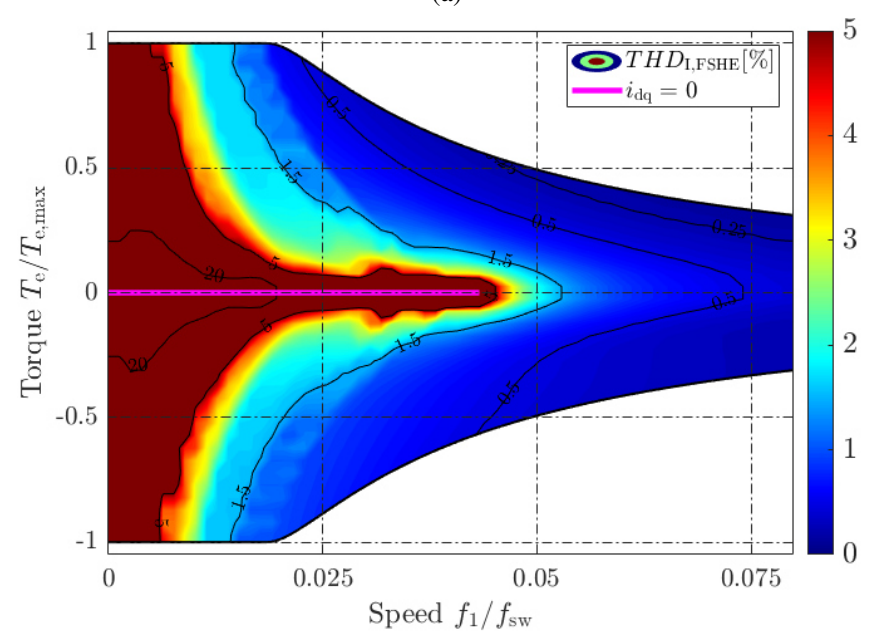

(b)

Fig. 7: Simulated current $T H D_{\mathrm{I}}$ for the entire drivetrain operating range for (a) MPWM and (b) FSHE.

$3.72 \mathrm{~V}$ and a rated capacity of $2800 \mathrm{mAh}$, which corresponds to about 10.42 Wh [28]. Furthermore, each H-bridge module is equipped with a small DC-link capacitor. Since the electric machine is operated at fundamental frequencies up to almost $1 \mathrm{kHz}$, the switching frequency, when using MPWM, is set to $10 \mathrm{kHz}$ [29], [30]. A full description of the modeled vehicle's power train model including the inverter and battery modeling and their parameter extraction can be found in [11].

To assess the performance of both modulation techniques, the current quality, characterized by the Total Harmonic Distortion (THD) of the current, and the combined efficiency of the inverter and the battery system are considered.

\section{Simulation Results}

\section{A. Output Current Quality - THD}

The obtained current $T H D_{\mathrm{I}}$ for the entire operating range of the drivetrain is depicted in Figs. 7(a) and 7(b) for MPWM and FSHE, respectively. As expected, at low modulation indices ( $M<0.25$ ), the current $T H D_{\mathrm{I}}$ is fairly high when using

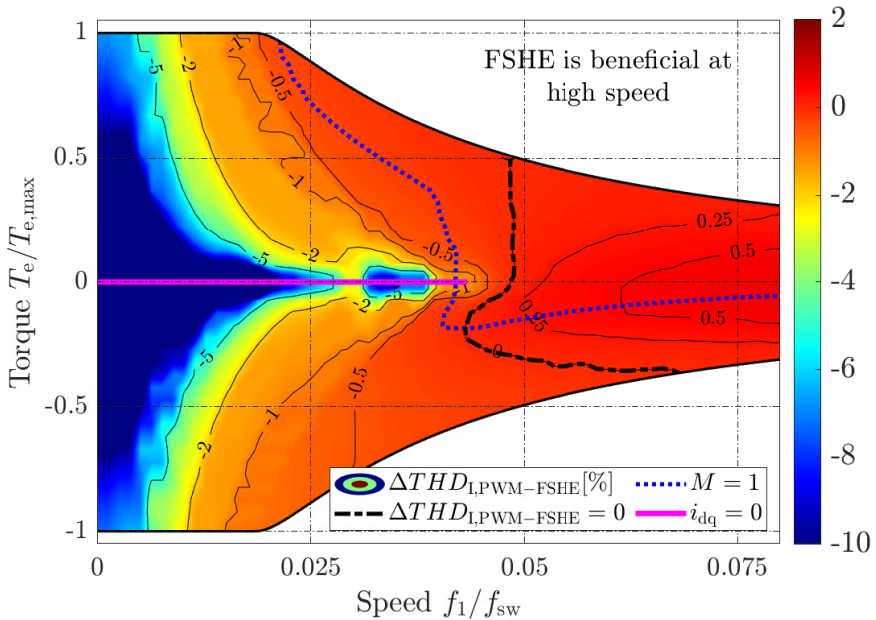

Fig. 8: Obtained simulated, absolute difference in current $T H D_{\mathrm{I}}$ between MPWM and FSHE, $\triangle T H D_{\mathrm{i}, \mathrm{PWM}-\mathrm{FSHE}}$.

FSHE, since none of the low order harmonic components can be eliminated. Calculating the absolute difference of the $T H D_{\text {I }}$ between MPWM and FSHE, the results as shown in Fig. 8 can be obtained. In terms of the current quality, it can be seen that FSHE becomes superior at higher speeds in relation to MPWM. The boundary is emphasized by the dashed black line. Considering just motor operation, the boundary between MPWM and FSHE with respect to the current $T H D_{\text {I }}$ can be roughly expressed as:

$$
\begin{aligned}
& \frac{f_{1}}{f_{\mathrm{sw}}} \geq 0.048 \rightarrow \text { FSHE } \\
& \frac{f_{1}}{f_{\mathrm{sw}}}<0.048 \rightarrow \mathrm{MPWM}
\end{aligned}
$$

\section{B. Inverter and Battery Efficiency $-\eta_{\text {Inv }} \& \eta_{\text {Bat }}$}

The simulated inverter efficiency for the entire operating range of the drivetrain is depicted in Figs. 9(a) and 9(b) for MPWM and FSHE, respectively. At low speed, MPWM is more efficient than FSHE, due to the reduced conduction losses. However, at higher speeds, FSHE, eliminating a selection of low order harmonics, becomes more efficient, because of the reduced switching losses. As can be seen, the inverter efficiency improvement using FSHE is not that significant, since the conduction losses of the MOSFETs are dominant in comparison to the switching losses.

Additionally, the simulated battery efficiency for the entire operating range of the drivetrain is depicted in Figs. 10(a) and 10(b) for MPWM and FSHE, respectively. As explained in [24], the battery modules are typically stressed with a dominant second order harmonic component, sometimes referred to as double power pulsation. Thus, as can be seen from the obtained efficiency results, the increased switching frequency, when using MPWM, increases the battery losses in comparison to FSHE.

Taking a look at the absolute difference of the combined battery and inverter efficiency $\eta_{\text {Inv }} \eta_{\text {Bat }}$, as shown in Fig. 11, 


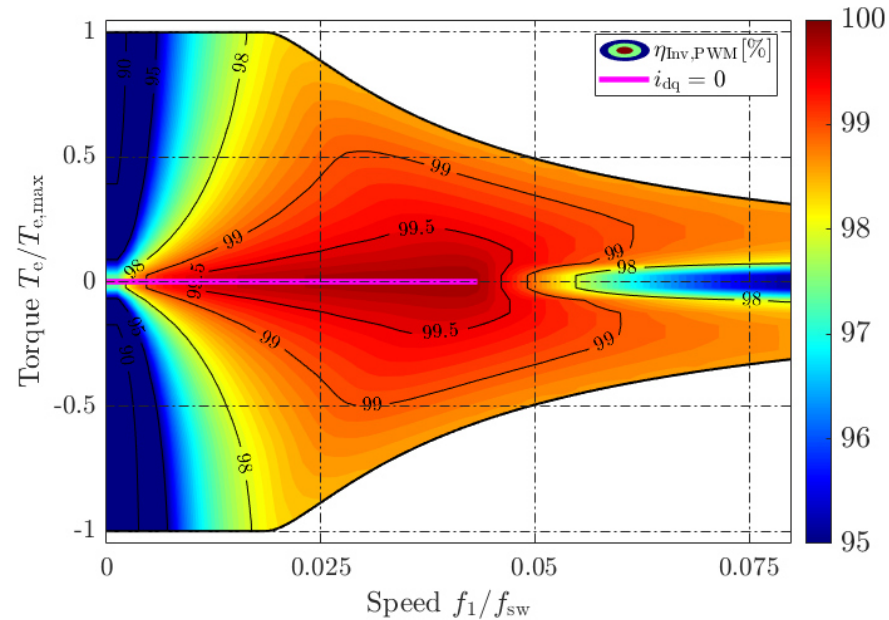

(a)

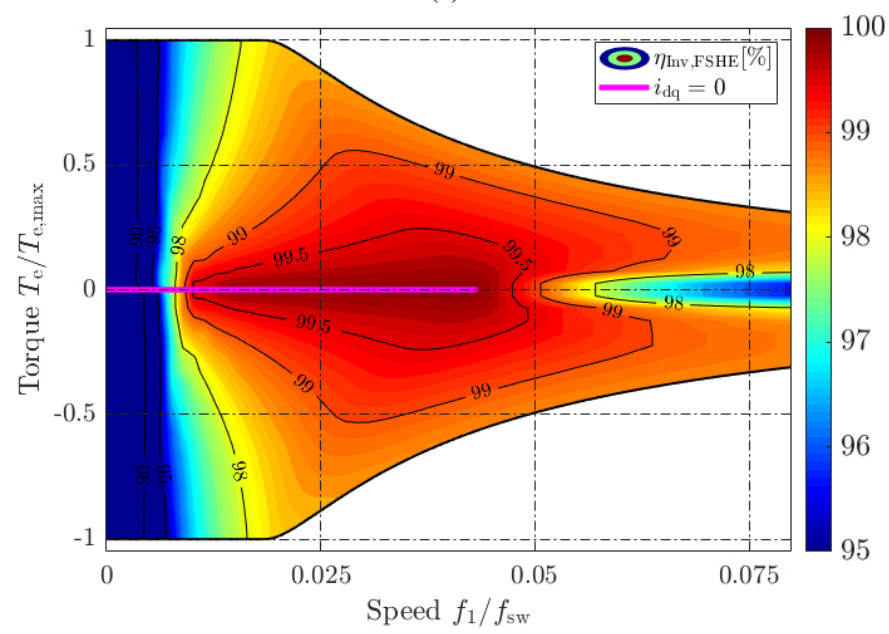

(b)

Fig. 9: Simulated inverter efficiency $\eta_{\mathrm{Inv}}$ for the entire drivetrain operating range for (a) MPWM and (b) FSHE.

it can be seen that FSHE achieves an improvement almost throughout the entire operating range. The zero boundaries are emphasized with the dashed black lines. Throughout the medium speed range, the absolute improvement of the drivetrain efficiency is up to about $5 \%$. Considering the drivetrain efficiency $\eta=\eta_{\text {Inv }} \eta_{\text {Bat }}$, the boundary between MPWM and FSHE can be roughly expressed as:

$$
\begin{gathered}
M \geq 0.25 \rightarrow \text { FSHE } \\
M<0.25 \rightarrow \text { MPWM } \\
\text { V. HYBRID OPERATION }
\end{gathered}
$$

The obtained simulation results are summarized in Fig. 12. As has been seen from the results, FSHE cannot be applied at low speed, because of the high current THD $_{\mathrm{I}}(>>5 \%)$. Nonetheless, if the modulation index exceeds 0.25, FSHE reduces the drivetrain losses, while maintaining an acceptable current $T H D_{\mathrm{I}}$. Further, at high speeds, if the the ratio of the fundamental frequency $f_{1}$ and the switching frequency $f_{\mathrm{sw}}$

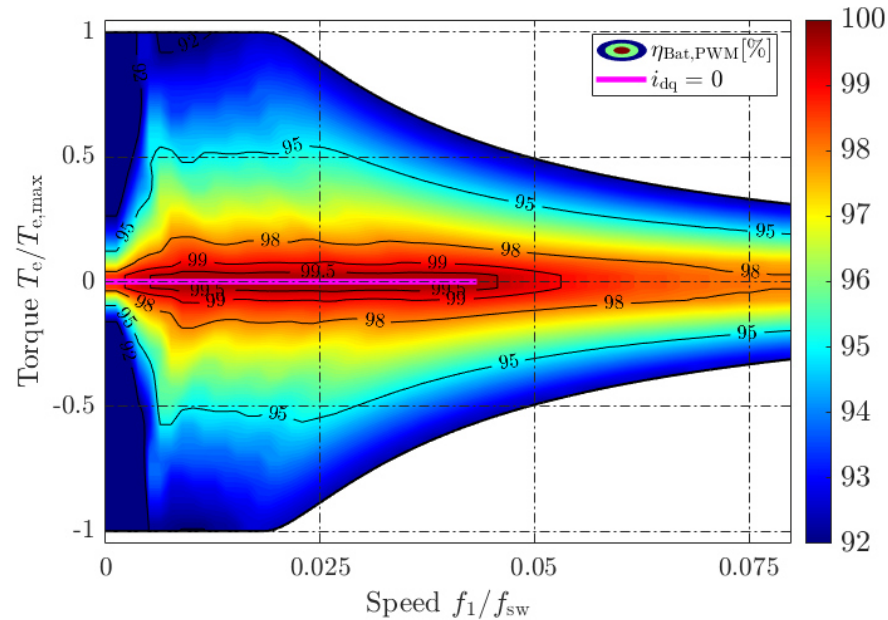

(a)

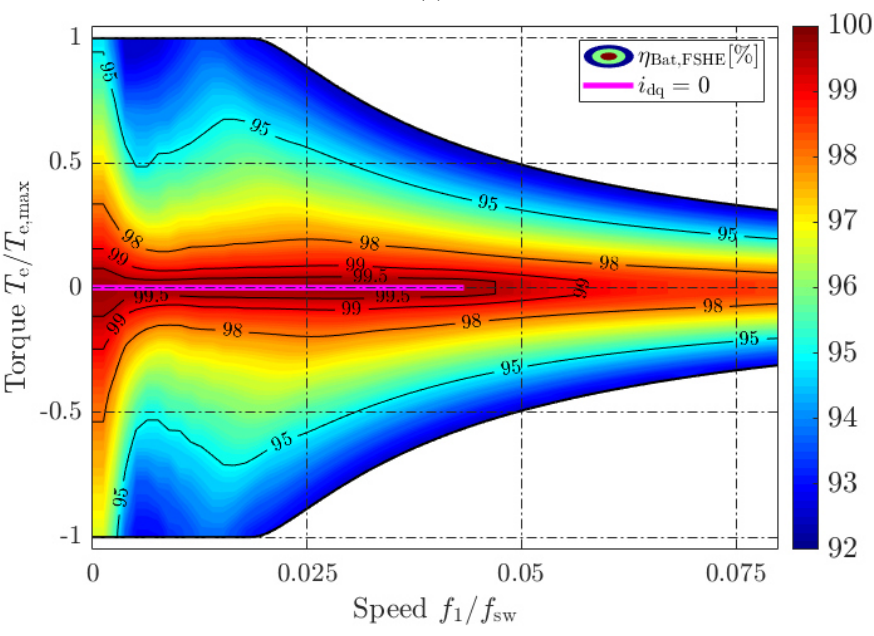

(b)

Fig. 10: Simulated battery efficiency $\eta_{\text {Bat }}$ for the entire drivetrain operating range for (a) MPWM and (b) FSHE.

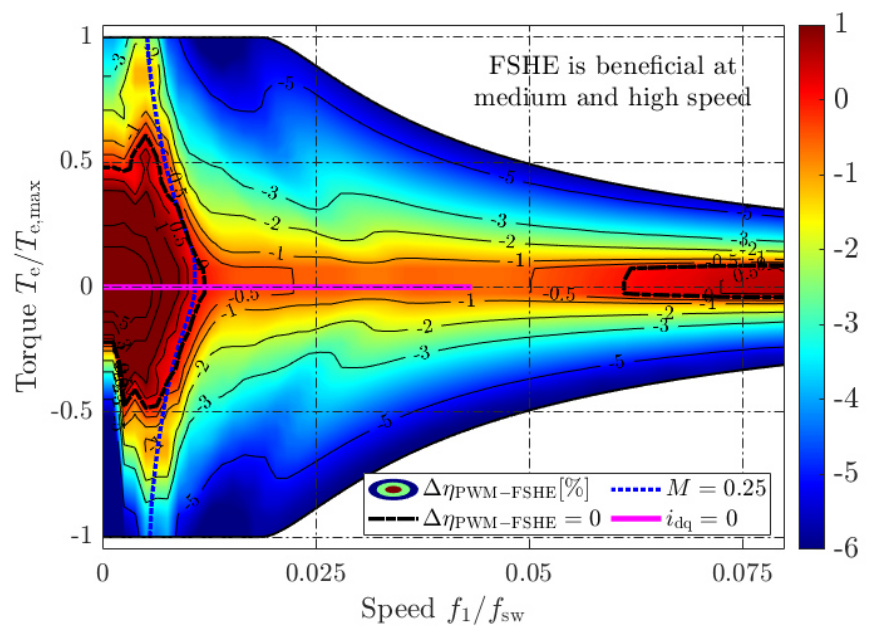

Fig. 11: Obtained simulated, absolute difference in combined inverter and battery efficiency $\eta_{\text {Inv }} \eta_{\text {Bat }}$ between MPWM and FSHE, $\Delta \eta_{\mathrm{PWM}-\mathrm{FSHE}}$. 


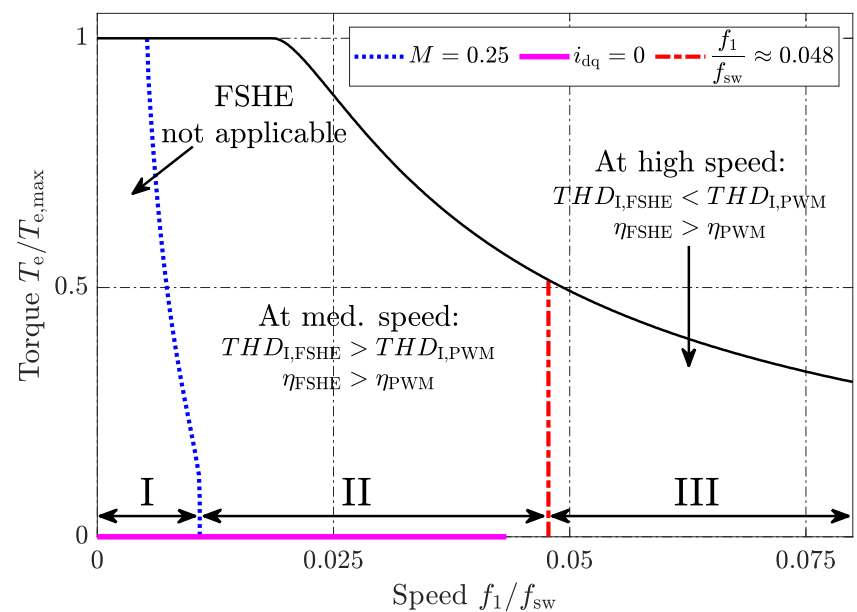

Fig. 12: Obtained beneficial operating regions for MPWM and FSHE in relation to the normalized torque and the relative vehicle speed with respect to the current $T H D_{\mathrm{I}}$ and the drivetrain efficiency $\eta=\eta_{\text {Inv }} \eta_{\text {Bat }}$.

exceeds 0.048 , FSHE is superior compared to MPWM in terms of the current $T H D_{\mathrm{I}}$ and the drivetrain efficiency. Therefore, it seems reasonable to operate the drive with a hybrid operation technique utilizing both MPWM and FSHE. The boundary between MPWM and FSHE should be selected to meet an optimization with respect to the individual weighting of current $T H D_{\mathrm{I}}$ and drivetrain efficiency $\eta=\eta_{\text {Inv }} \eta_{\text {Bat }}$.

\section{CONCLUSION}

This paper has analyzed the output current $T H D_{\mathrm{I}}$ as well as the inverter and battery efficiency of a seven level CHB inverter drivetrain used in a small passenger vehicle when operated with multilevel pulse width modulation and fundamental selective harmonic elimination. It has been seen that FSHE is not applicable, if the modulation index is below 0.25 . Nonetheless, exceeding a modulation index of 0.25 , FSHE improves the drivetrain efficiency and at high speed it even reduces the current $T H D_{\text {I }}$ in comparison to MPWM. Thus, it has been concluded that it is the most beneficial to operate the CHB inverter with a hybrid output voltage modulation technique. At low speed and stand still, the drivetrain must be operated with MPWM, whereas at higher speeds FSHE should be selected. The boundary between MPWM and FSHE is dependent on the modulation index $M$ and the relative vehicle speed $\frac{f_{1}}{f_{\mathrm{sw}}}$. It should be selected in a manner to meet an optimization relative to the individual current $T H D_{\mathrm{I}}$ and drivetrain efficiency $\eta_{\text {Inv }} \eta_{\text {Bat }}$ weightings.

\section{ACKNOWLEDGMENT}

The financial support provided by the Swedish Energy Agency is gratefully acknowledged.

\section{REFERENCES}

[1] E. A. Grunditz and T. Thiringer, "Performance analysis of current bevs based on a comprehensive review of specifications," IEEE Transactions on Transportation Electrification, vol. 2, no. 3, pp. 270-289, 2016.

[2] S. Brueske, S. Walz, M. Liserre, and F. W. Fuchs, "Loss balancing of three-level inverters in electric vehicles for low speed operation," in 2016 18th European Conference on Power Electronics and Applications (EPE'16 ECCE Europe). IEEE, 2016, pp. 1-10.

[3] A. Kersten, E. Grunditz, and T. Thiringer, "Efficiency of active threelevel and five-level npc inverters compared to a two-level inverter in a vehicle," in 2018 20th European Conference on Power Electronics and Applications (EPE'18 ECCE Europe). IEEE, 2018, pp. P-1.

[4] E. A. Grunditz, T. Thiringer, and N. Saadat, "Acceleration, drive cycle efficiency and cost trade-offs for scaled electric vehicle drive system," IEEE Transactions on Industry Applications, 2020.

[5] O. Josefsson, T. Thiringer, S. Lundmark, and H. Zelaya, "Evaluation and comparison of a two-level and a multilevel inverter for an ev using a modulized battery topology," in IECON 2012-38th Annual Conference on IEEE Industrial Electronics Society. IEEE, 2012, pp. 2949-2956.

[6] E. Behrouzian and M. Bongiorno, "Investigation of negative-sequence injection capability of cascaded h-bridge converters in star and delta configuration," IEEE Transactions on Power Electronics, vol. 32, no. 2 pp. 1675-1683, 2017.

[7] E. Behrouzian, M. Bongiorno, and R. Teodorescu, "Impact of switching harmonics on capacitor cells balancing in phase-shifted pwm-based cascaded h-bridge statcom," IEEE Transactions on Power Electronics, vol. 32, no. 1, pp. 815-824, 2017.

[8] E. Behrouzian, M. Bongiorno, R. Teodorescu, and J. Hasler, "Individual capacitor voltage balancing in h-bridge cascaded multilevel statcom at zero current operating mode," in 2015 17th European Conference on Power Electronics and Applications (EPE'15 ECCE-Europe), 2015, pp. $1-10$.

[9] O. Josefsson, Investigation of a multilevel inverter for electric vehicle applications. Chalmers University of Technology, 2015.

[10] F. Z. Peng, W. Qian, and D. Cao, "Recent advances in multilevel converter/inverter topologies and applications," in The 2010 International Power Electronics Conference-ECCE ASIA-. IEEE, 2010, pp. 492-501.

[11] A. Kersten, M. Kuder, E. Grunditz, Z. Geng, E. Wikner, T. Thiringer, T. Weyh, and R. Eckerle, "Inverter and battery drive cycle efficiency comparisons of chb and mmsp traction inverters for electric vehicles," in 201921 st European Conference on Power Electronics and Applications (EPE'19 ECCE Europe). IEEE, 2019, pp. P-1.

[12] L. M. Tolbert, F. Z. Peng, and T. G. Habetler, "Multilevel inverters for electric vehicle applications," in Power Electronics in Transportation (Cat. No. 98TH8349). IEEE, 1998, pp. 79-84.

[13] M. Marchesoni, "High-performance current control techniques for application to multilevel high-power voltage source inverters," IEEE Transactions on Power Electronics, vol. 7, no. 1, pp. 189-204, 1992.

[14] E. Wikner and T. Thiringer, "Extending battery lifetime by avoiding high soc," Applied Sciences, vol. 8, no. 10, p. 1825, 2018.

[15] J.-S. Lai and F. Z. Peng, "Multilevel converters-a new breed of power converters," IEEE Transactions on industry applications, vol. 32, no. 3, pp. 509-517, 1996.

[16] M. Kuder, A. Kersten, L. Bergmann, R. Eckerle, F. Helling, and T. Weyh, "Exponential modular multilevel converter for low voltage applications," in 2019 21st European Conference on Power Electronics and Applications (EPE'19 ECCE Europe). IEEE, 2019, pp. P-1.

[17] A. Kersten, K. Oberdieck, J. Gossmann, A. Bubert, R. Loewenherz, M. Neubert, E. Grunditz, T. Thiringer, and R. W. De Doncker, " $\mathrm{Cm}$ \& line-dm noise separation for three-level npc inverter with connected neutral point for vehicle traction applications," in 2019 IEEE Transportation Electrification Conference and Expo (ITEC). IEEE, 2019, pp. 1-6.

[18] O. Josefsson, A. Lindskog, S. Lundmark, and T. Thiringer, "Assessment of a multilevel converter for a phev charge and traction application," in The XIX International Conference on Electrical Machines-ICEM 2010. IEEE, 2010, pp. 1-6.

[19] F. Chang, O. Ilina, M. Lienkamp, and L. Voss, "Improving the overall efficiency of automotive inverters using a multilevel converter composed of low voltage si mosfets," IEEE Transactions on Power Electronics, vol. 34, no. 4, pp. 3586-3602, 2019.

[20] K. Corzine and Y. Familiant, "A new cascaded multilevel h-bridge drive," IEEE Transactions on power electronics, vol. 17, no. 1, pp. 125-131, 2002. 
[21] A. Kersten, K. Oberdieck, A. Bubert, M. Neubert, E. A. Grunditz, T. Thiringer, and R. W. De Doncker, "Fault detection and localization for limp home functionality of three-level npc inverters with connected neutral point for electric vehicles," IEEE Transactions on Transportation Electrification, vol. 5, no. 2, pp. 416-432, 2019.

[22] M. D. Manjrekar and T. A. Lipo, "A hybrid multilevel inverter topology for drive applications," in Proc. APEC, vol. 2, 1998, pp. 523-9.

[23] C. Korte, E. Specht, M. Hiller, and S. Goetz, "Efficiency evaluation of mmspc/chb topologies for automotive applications," in 2017 IEEE 12th International Conference on Power Electronics and Drive Systems (PEDS). IEEE, 2017, pp. 324-330.

[24] A. Kersten, O. Theliander, E. A. Grunditz, T. Thiringer, and M. Bongiorno, "Battery loss and stress mitigation in a cascaded h-bridge multilevel inverter for vehicle traction applications by filter capacitors," IEEE Transactions on Transportation Electrification, vol. 5, no. 3, pp. 659-671, 2019.

[25] J. Cao, N. Schofield, and A. Emadi, "Battery balancing methods: A comprehensive review," in 2008 IEEE Vehicle Power and Propulsion Conference, 2008, pp. 1-6.

[26] A. Stippich, C. H. Van Der Broeck, A. Sewergin, A. H. Wienhausen, M. Neubert, P. Schülting, S. Taraborrelli, H. van Hoek, and R. W. De Doncker, "Key components of modular propulsion systems for next generation electric vehicles," CPSS Transactions on Power Electronics and Applications, vol. 2, no. 4, pp. 249-258, 2017.

[27] D. G. Holmes and T. A. Lipo, Pulse width modulation for power converters: principles and practice. John Wiley \& Sons, 2003, vol. 18.

[28] LG Chem, "Product Description: ICR18650 C2 2800mAh," https://www. batteryspace.com/prod-specs/5702 5.pdf, (Accessed on 05/04/2019).

[29] L. Harnefors, Control of variable-speed drives. Applied Signal Processing and Control, Department of Electronics, Mälardalen ..., 2002.

[30] K. Sharifabadi, L. Harnefors, H.-P. Nee, S. Norrga, and R. Teodorescu, Design, control, and application of modular multilevel converters for HVDC transmission systems. John Wiley \& Sons, 2016. 